\title{
Educação em saúde da pessoa idosa em discursos e práticas: atividade fisica como sinônimo de sáde *
}

Wânia Ribeiro Fernandes ${ }^{1}$

Vera Helena Ferraz de Siqueira ${ }^{2}$

FERNANDES, W.R.; SIQUEIRA, V.H.F. Health education for elderly people in discourse and practice: physical activity as a synonym for health. Interface - Comunic., Saude, Educ., v.14, n.33, p.371-85, abr./jun. 2010.

In this paper, we present a discussion on health education and health promotion among elderly people, based on empirical studies of qualitative nature is presented, with the aim of analyzing the ways in which discourse is produced within the political sphere and how these are subjectivated. We obtained the data through semistructured interviews with elderly people and with professionals who were directly involved in implementing public healthcare policies geared towards the elderly population. After briefly discussing the recommended guidelines for such policies, we present the results. These show that professionals regard physical activity as the principal strategy for promoting "healthy old age", and that elderly people's discourse reproduces these constructions to a large extent. Foucault's notion of biopower and some notions stemming from cultural studies helped us to understand how individuals are subjectivated in relation to what is advocated as a healthy way to live.

Keywords: Discourse. Health education. Health promotion. Elderly people. Biopower.
Neste artigo apresentamos uma discussão acerca da educação e promoção em saúde da pessoa idosa com base em estudo empírico de cunho qualitativo, que teve por objetivo analisar os modos como os discursos são produzidos no âmbito político e como são subjetivados. Obtivemos os dados a partir de entrevistas semiestruturadas realizadas com idosos(as) e profissionais diretamente envolvidos na implementação das políticas públicas de saúde voltadas à população idosa. Após breve discussão das diretrizes preconizadas por tais políticas, apresentamos os resultados, os quais evidenciam que os profissionais significam a atividade física como principal estratégia para a promoção de uma "velhice saudável" e que os discursos dos idosos reproduzem, em grande medida, essas construções. A noção foucaultiana de biopoder e algumas noções advindas dos estudos culturais nos ajudaram a entender como os indivíduos são subjetivados em relação ao que é preconizado como modo saudável de viver.

Palavras-chave: Discursos. Educação em saúde. Promoção da saúde. Idosos. Biopoder.
Elaborado com base em Fernandes (2010), pesquisa com

financiamento Capes, aprovada pela Comitê de Ética e Pesquisa de universidade situada no município onde ocorreu (Proc. $n^{\circ}$ 025/08). ${ }^{1}$ Doutoranda em Educação em Ciências e Saúde, Núcleo de Tecnologia Educacional para a Saúde,

Universidade Federal do Rio de Janeiro (Nutes/ UFRJ). Rua Soares de Miranda, 135/1304.

Fonseca, Niterói, RJ, Brasil. 24.120-307. waniafer@hotmail.com ${ }^{2}$ Nutes, UFRJ. 


\section{Introdução}

Este artigo trata da dinâmica, em curso na atualidade, que identifica a prática de exercícios físicos como a principal estratégia para a promoção de um envelhecimento saudável. Entendemos que essa lógica contemporânea de pensar a educação, a prevenção e a promoção de saúde, tão evidente no contexto brasileiro, institui um paradigma reducionista, quando se tem em vista a complexidade que envolve a questão e os múltiplos aspectos concernentes à manutenção da saúde e à capacidade funcional da pessoa idosa.

O rápido processo de envelhecimento populacional no Brasil, deflagrado na década de 1960, produziu graves consequências tanto no âmbito das políticas públicas quanto na implementação de programas para a pessoa idosa. Na atualidade, este grupo populacional continua sendo o que mais cresce proporcionalmente em todas as regiões do país. Tais mudanças na composição populacional vêm acarretando alterações sociais, culturais e epidemiológicas, como, por exemplo, isolamento social, conflito intergeracional e aumento significativo de doenças crônicas não-transmissíveis, demandando urgência na priorização de ações preventivas (Kalache, 2008; Camarano, 2004).

Nos últimos tempos tem sido possível identificar múltiplos discursos associados ao envelhecimento e às ações voltadas a este segmento, provenientes de diretrizes governamentais, de gestores públicos e da mídia, entre outros. Perdem força as referências à "velhice" 3 como um peso tanto para a família quanto para o Estado ("fardo da humanidade", "estorvo social" e/ou "parasitas inúteis") 4 . Tornam-se cada vez mais frequentes aquelas que preconizam a manutenção da "qualidade de vida" e o "envelhecimento saudável", entendidos a partir da possibilidade de as pessoas viverem de forma autônoma e independente na comunidade por meio de ações de educação e de promoção em saúde.

Neste artigo, apresentamos uma discussão acerca dos entendimentos sobre educação e promoção em saúde da pessoa idosa com base em estudo empírico, que teve por objetivo analisar os modos como os discursos são produzidos no âmbito político e de que maneira estes mesmos discursos, consubstanciados nas práticas, são subjetivados.

Essa discussão é feita também com base em documentos relacionados às diretrizes preconizadas pelas políticas públicas de saúde, sobretudo aqueles voltados para a pessoa idosa no Brasil. Tendo esses aspectos em vista, problematizamos as noções de promoção e de educação em saúde, defendendo uma visão mais ampla, que contemple a subjetividade dos indivíduos e os inúmeros fatores de ordem política, econômica e social concernentes às questões da saúde e da educação do(a) idoso(a).

Utilizamos, mais especificamente, os conceitos foucaultianos de biopoder e de biopolítica para embasar a análise dos discursos sobre promoção e educação em saúde. Alguns autores da linha crítica da educação em saúde, que dialogam com certos deslocamentos contemporâneos, e autores identificados com a educação popular nos ajudaram a refletir sobre uma proposta de educação em saúde na terceira idade mais alinhada com a complexidade e as múltiplas dimensões do envelhecimento humano.

Os resultados da pesquisa evidenciaram tanto que os profissionais significam a atividade física como principal estratégia para a promoção de um envelhecimento saudável, por meio da introdução dos exercícios físicos regulares e diários, como que os discursos dos(as) idosos(as) reproduzem, em grande medida, essas construções.

\author{
${ }^{3}$ Optamos por empregar \\ o termo idoso(a) neste \\ artigo; entretanto \\ julgamos pertinente \\ usar, em alguns \\ momentos, a palavra \\ velhice no sentido de \\ "categoria social, mais \\ ou menos valorizada \\ segundo as \\ circunstâncias", como \\ descrito por Beauvoir \\ (1990, p.109), e o \\ termo envelhecimento, \\ quando nos referimos ao \\ processo de envelhecer. \\ ${ }^{4}$ Expressões usadas em \\ referência ao idoso, \\ conforme pesquisa \\ realizada por Paz (1997), \\ e apresentadas na \\ publicação: Espelho, \\ espelho meu... imagens \\ que povoam o \\ imaginário social da \\ velhice e do idoso.
}




\section{O envelhecimento no Brasil: desafios para a promoção e a educação em saúde}

O processo de envelhecimento populacional mundial é fator marcante na contemporaneidade. Entretanto, nos países em desenvolvimento, como o Brasil, o crescimento da população idosa vem se constituindo de forma rápida e associado a múltiplas deficiências. A partir de 1970 observou-se significativa desaceleração no crescimento da população jovem, enquanto o grupo com sessenta anos ou mais cresceu proporcionalmente em todas as regiões brasileiras. De 1980 até o ano 2000 , o grupo de zero a 14 anos cresceu apenas $14 \%$ contra $107 \%$ do grupo de sessenta anos ou mais. Tal processo trouxe grandes repercussões para o sistema nacional de saúde, o previdenciário, o econômico e para a vida social (Bahia, 2008; Camarano, 2004).

No Brasil, o envelhecimento populacional caracteriza-se por ser senil e acompanhado de múltiplas patologias. Com um contingente estimado de vinte milhões em 2008, os(as) idosos(as) brasileiros(as) sofrem as consequências de uma sociedade com graves problemas relativos à distribuição de renda, à violência, ao acesso aos serviços públicos de saúde básica e a atitudes de discriminação e de exclusão associadas ao gênero, à etnia, às condições socioeconômicas, à região geográfica de origem e à localização de moradia. Tais fatores imprimem uma complexa diversidade aos modos de envelhecer brasileiro (Veras, 2009; Brasil, 2006).

O tema envelhecimento ativo e saudável surge no cenário nacional apenas no final do século XX, através da Política Nacional de Saúde do Idoso (PNSI), redefinindo novas estratégias para a promoção e a prevenção de saúde no envelhecimento. Por meio do conceito de "capacidade funcional", entendida como aquela de manutenção das habilidades físicas e mentais necessárias para a vida independente e autônoma, a PNSI procurou instrumentalizar e operacionalizar a atenção à saúde do idoso, estimulando ações preventivas, assistenciais e de reabilitação.

Com a promulgação da Política Nacional de Saúde da Pessoa Idosa (PNSPI) por meio da Portaria $n^{\circ} 2.528$, em 19 de outubro de 2006, o governo trouxe o atendimento à pessoa idosa, através da Estratégia de Saúde da Família (ESF), para a rede de atenção básica (Brasil, 2006, 1999).

Ao deslocar a rede de atenção à pessoa idosa para o nível básico, a estratégia governamental buscou garantir a atenção integral à saúde da população idosa de baixa renda, que apresenta, com frequência, algum tipo de agravo. Medidas coletivas e individuais destinavam-se a manter e promover a autonomia e a independência conforme os princípios e as diretrizes do Sistema Único de Saúde (SUS).

Contudo, nem a aprovação do Estatuto do Idoso em 2003 nem a PNSPI viabilizaram as ações que propunham notadamente a atenção à saúde da pessoa idosa de forma integral e multidisciplinar em todos os níveis de atenção, caracterizando-se como movimentos pontuais e desarticulados no país. Nesse contexto, as questões da promoção e da educação em saúde apontam importantes desafios para a implementação dessas políticas (Veras, 2009).

Originalmente, o termo Promoção em Saúde ${ }^{5}$ surge associado à saúde pública, mais especificamente à medicina. Foi a necessidade de controle dos altos custos, decorrente do modelo de assistência médica curativa de alta tecnologia desenvolvido nos países industrializados, que fez emergir discussões sobre ações de saúde capazes de resgatar o modelo médico social inglês prevalente no século XIX, com o que se conseguiu reduzir as taxas de mortalidade, melhorando as condições do meio ambiente (saneamento), da nutrição e do comportamento de reprodução da populaçãó. 
O objetivo final seria a redução do papel do Estado no financiamento das ações de saúde. Para tal, identifica-se um estímulo às ações de empowerment ou do processo de capacitar, de fortalecer os indivíduos e as comunidades, por intermédio da ênfase no autocuidado, na autonomia e na independência. Tal perspectiva retira, cada vez mais, a responsabilidade do Estado de cuidar da saúde da população e delega, a sujeitos e grupos sociais específicos, a tarefa de cuidarem de si mesmos (Buss, 2003).

Após a década de 1970, os discursos oficiais e acadêmicos sobre o tema "Promoção da Saúde" no Brasil caracterizam-se por estabelecerem relações entre saúde e sociedade, identificando os processos econômicos e políticos desenvolvidos no país como sendo a origem dos perfis epidemiológicos complexos que criaram situações de intensa desigualdade (Brasil, 2002a, 1999, 1975, 1973; Monteiro, Benício, Freitas, 1997; Singer, Campos, Oliveira, 1978; Macedo, 1977).

O entendimento de que a saúde tem determinações que vão além das biológicas e genéticas, como as políticas e culturais, fez com que a promoção passasse a ser entendida como responsabilidade tanto da população organizada quanto de atores de outros setores sociais, não necessariamente da área da saúde.

Segundo "As Cartas da Promoção da Saúde", publicadas pelo Ministério da Saúde em 2002, a promoção tem foco específico na saúde e suas proposições destinam-se a manter e melhorar seu nível. A promoção é definida como: " [...] processo de capacitar indivíduos e comunidades para aumentar o controle sobre os determinantes da saúde e, assim, incrementar sua saúde [...], devendo para isto um indivíduo ou grupo ser capaz de identificar e realizar aspirações, satisfazer necessidades e mudar ou controlar o ambiente". (Brasil, 2002a, p.19)

Alguns documentos decorrentes das Conferências Internacionais sobre Promoção da Saúde conferem destaque específico ao papel da Educação neste processo, adotando uma visão ampliada de saúde, que reconhece o papel de fatores que contribuem para a qualidade das "condições de vida" do sujeito, como alimentação e saneamento. Neste sentido, em 1978, a Declaração de Alma-Ata, resultante da primeira Conferência Internacional sobre Cuidados Primários de Saúde, indica a Educação como área que a atenção primária à saúde necessita contemplar, especificando que os "cuidados primários de saúde" devem minimamente prever: "[...] educação, no tocante a problemas prevalecentes de saúde e aos métodos para sua prevenção e controle, promoção da distribuição de alimentos e da nutrição apropriada, previsão adequada de água de boa qualidade e saneamento básico [...]" (Brasil, 2002a, parágrafo VII, item 3).

A Declaração de Adelaide, de 1988, aponta para a importância de as instituições educacionais reorientarem seus currículos para as necessidades da "nova saúde pública" a fim de "melhorar as habilidades em capacitação, mediação e defesa da saúde pública".

Em 1991, a Declaração de Sundsvall alerta para a urgência de os países atingirem maior nível de justiça social em saúde, indicando que as ações "devem envolver, predominantemente, setores como educação, transporte, habitação, e desenvolvimento urbano". Reconhece ainda a educação como direito básico e "elemento-chave" para ocorrerem mudanças políticas, econômicas e sociais, "necessárias para tornar a saúde possível para todos". É possível relacionar tais indicações ao discurso bastante prevalente na atualidade que enfatiza a importância do desenvolvimento da cidadania e empowerment dos diversos grupos sociais.

A Declaração de Santafé de Bogotá decorre da Conferência que tratou, em especial, da saúde na América Latina em 1992. Esse documento, além de apontar as especificidades das condições de saúde da América Latina, reforça a importância da participação ativa das pessoas para que ocorram mudanças sanitárias. Destaca o "repasse de informação e a promoção do conhecimento" como "valiosos instrumentos" para a mudança de estilos de vida nas comunidades. Aponta também para a necessidade de se "fortalecer a capacidade da população nas tomadas de decisões que afetem sua vida e para optar por estilos de vida saudáveis".

Há um tensionamento neste discurso, na medida em que a autonomia dos sujeitos ganha centralidade e, ao mesmo tempo, o ato educativo é postulado, de forma instrumental, em função da mudança de comportamento obtida por meio do "repasse de informação". 
${ }^{7}$ A Declaração de Jacarta se ocupou do tema saúde no século $X X I$ e determinou, como prérequisitos para a saúde: a existência de paz, abrigo, instrução, segurança social, relações sociais, alimento, renda; o direito de voz das mulheres; a estabilidade do ecossistema; o uso sustentável dos recursos; a justiça social; o respeito aos direitos humanos, e a equidade.

\footnotetext{
${ }^{8}$ A Declaração de Bangkok se ocupou do tema Promoção da saúde em um mundo

globalizado e buscou

identificar ações, compromissos e

promessas necessários

para se abordarem os

determinantes da saúde em um mundo

globalizado por meio da promoção.
}

Na Declaração de Jacarta de 1997 7 a questão do envelhecimento demográfico mundial é ressaltada pela primeira vez, associada à prevalência de doenças crônicas e ao comportamento sedentário, requerendo "urgentes providências" para o desenvolvimento da promoção da Saúde.

Em 2005, consonante com o apelo da Declaração de Bangkok ${ }^{8}$ no sentido de diminuir a distância entre discursos e práticas, o Ministério da Saúde definiu a "Agenda de Compromisso pela Saúde", da qual destacamos "O Pacto em Defesa da Vida" por constituir o conjunto de ações sanitárias a serem priorizadas pela Federação, pelos Estados e pelos Municípios.

A relação que nos interessa aqui, entre saúde e atividade física, surge oficialmente no Brasil, pela primeira vez, no Plano de Ação Internacional para o Envelhecimento. Resultado da II Assembléia Mundial do Envelhecimento (realizada em abril de 2002 em Madri, Espanha, e promovida pela ONU), preconiza uma "Sociedade para todas as idades" e, para atingir este objetivo, contém três direcionamentos: 1 Idosos e desenvolvimento; 2 Saúde avançada e bem-estar para a terceira idade, e 3 Garantia de ambiente de capacitação e de apoio, com 18 questões prioritárias, 35 objetivos e 239 recomendações para a ação. No Direcionamento 2, o Tema I: Promoção da saúde e do bem-estar durante toda a vida, item 66, tem como objetivo 1: "redução dos efeitos cumulativos dos fatores que aumentam o risco de sofrer doenças e, em consequência, a possível dependência na velhice". Para tal, propõe, como uma das medidas, "concentrar as atividades de Promoção da Saúde, de educação sanitária, das políticas de prevenção e das campanhas de informação nos conhecidos e importantes riscos de uma dieta pouco saudável, da falta de atividade física e de outras formas de comportamento perniciosos para a saúde, como o hábito de fumar e o abuso do álcool" (item e) (Organização das Nações Unidas, 2002, p.51-5).

O documento enfatiza a necessidade de se fortalecer e qualificar a "promoção, informação e educação em saúde com ênfase na promoção de atividade física, na promoção de hábitos saudáveis de alimentação e vida, no controle do tabagismo; controle do uso abusivo de bebida alcoólica e cuidados especiais voltados ao processo de envelhecimento". O texto aponta claramente para o comprometimento governamental com as ações de Educação em Saúde e dá relevância à atividade física como estratégia de promoção à saúde.

$\mathrm{Na}$ atualidade, esse entendimento sobre os pressupostos que orientam as escolhas tidas como "saudáveis" pelos sujeitos e pelos grupos sociais é determinante para o encaminhamento das práticas sanitárias e de saúde. A incorporação de outras dimensões na percepção da saúde - conhecimentos, valores e crenças - tornou-se essencial para uma reflexão crítica sobre os desafios contemporâneos das práticas de saúde e sobre a origem das dificuldades que surgem na operacionalização dos projetos (Brasil, 2002b).

Para que se promova efetivamente a saúde, é preciso que se avance para além da perspectiva biomédica, calcada na intervenção clínica, com ênfase na transformação do comportamento individual visto como o principal - quando não, o único - responsável pelo estado de saúde do indivíduo, para uma estratégia de mediação entre pessoas e ambiente, em que se torne possível combinar escolhas individuais com políticas públicas saudáveis.

São frequentes as simplificações que equiparam a Educação em Saúde à transmissão de informação em saúde, como quando políticos, administradores de serviços de saúde e médicos, entre outros(as), presumem que dizer às pessoas o que devem fazer para serem saudáveis é o mesmo que educar. Tal entendimento 
reducionista pressupõe um aprendizado instantâneo, por meio de processos unidirecionais de um polo que detém o conhecimento e informações para outro - o(a) educando(a) - destituído de história, de saberes e de motivações.

Candeias (1997) comenta que vários estudos têm utilizado os termos educação em saúde e promoção em saúde como sinônimos, e esta confusão conceitual tem afetado a qualidade das discussões técnicas relativas às intervenções sociais na área de saúde pública. Esclarecer tais significados seria pressuposto para a compreensão clara de seus objetivos, de sua abrangência e de seus propósitos, e possibilitaria distinguir tipos de programas, de atividades e de procedimentos que caracterizam as respectivas propostas, visto que ambos procuram contribuir para o desenvolvimento de melhores níveis de saúde da população.

Enfatizamos a polissemia que marca essas noções e os diferentes entendimentos mantidos sobre elas ao longo dos tempos. Para atender aos importantes desafios trazidos para o Sistema de Saúde pelo acelerado processo de transição demográfica e epidemiológica mundial, a Promoção avança de uma abordagem inicialmente focada na transformação dos comportamentos dos indivíduos ou de seu "estilo de vida" para o entendimento de que "saúde" é produto de uma extensa gama de fatores relacionados às "condições de vida" do sujeito, como: saneamento, boas oportunidades de emprego e renda, habitação adequada, acesso e oportunidades de educação ao longo da vida, assim como a boa alimentação.

A compreensão da Educação em Saúde como o conjunto de todas as ações que determinam conhecimento, crenças e comportamentos dos indivíduos e da coletividade empresta maior produtividade a essa noção, na medida em que se assume que o fundamental não é identificar se tais "aprendizagens" se deram em espaço formal ou informal de educação, em contexto familiar, escolar ou social. O mais importante é entender a grande variedade de circunstâncias e de locais onde as influências sobre o comportamento individual e coletivo podem se dar, beneficiando-o ou não, mesmo que sem qualquer intenção específica para a saúde (Downie,Tannahill, Tannahill, 1996).

Isso não implica desvalorizar os espaços formais de educação e as metodologias específicas desenvolvidas com o intuito de "facilitar" ou levar o indivíduo a "incorporar" ações voluntárias em direção à saúde. Contudo, aponta para a complexidade que envolve a Educação, enquanto processo: se quaisquer combinações de experiências podem levar à aprendizagem, importante será identificar os múltiplos determinantes do comportamento saudável, sejam eles programados ou acidentais (Buss, 1999).

Partindo dessa concepção ampla do processo saúde-adoecimento e de seus determinantes, a Promoção da Saúde passa a propor: a articulação de saberes técnicos e populares, a mobilização de recursos públicos e privados, individuais e coletivos, para o enfrentamento dos problemas de saúde e seus determinantes, tendo a Educação em Saúde como importante componente neste sistema.

Esses múltiplos discursos políticos e da promoção e educação em saúde instituem certas verdades sobre os indivíduos, que são subjetivadas em relação a determinados estilos de vida e modos de ser.

\section{O corpo como local de investimento através dos discursos oficiais e de pessoas idosas}

Como apontado por Foucault (2002), é necessário que haja condições históricas para o aparecimento de um "objeto de discurso", uma vez que não seria possível falar sobre qualquer coisa em qualquer momento. Assim, essa preocupação de intervir nos "determinantes do adoecimento humano" decorre da grande crise instalada nos sistemas de saúde, que não mais conseguiam gerir as "doenças", intervindo apenas no processo de cura.

Discursos e práticas guiados por tal orientação passam a ser dirigidos especificamente para a população idosa durante as últimas décadas, sobretudo em função do aumento desse segmento da população, com as consequentes repercussões que tem para o sistema. Dentre as "diretrizes essenciais" norteadoras das ações no setor saúde, ganha relevância, no âmbito da promoção do envelhecimento saudável, o desenvolvimento daquelas que orientam os(as) idosos(as) e as pessoas em processo de envelhecimento sobre a importância da adoção precoce de hábitos saudáveis de vida para a melhoria de suas habilidades funcionais. 
${ }^{9}$ Todos(as) os participantes da pesquisa foram voluntários e receberam informação prévia sobre a natureza da mesma, assinando o Termo de Consentimento Livre e Esclarecido (TCLE), conforme preconizado pela Comissão Nacional de Ética em Pesquisa (CONEP).

${ }^{10}$ Este é um Programa implementado pela Secretaria Municipal de Saúde, que presta atendimento às pessoas idosas, contudo não se destina apenas a este segmento populacional. Sua função é dar informação e orientação a todas as pessoas hipertensas e/ou diabéticas.

${ }^{11}$ Um conjunto de seis aparelhos para ginástica montado em praças públicas. Este projeto originariamente surgiu em Maringá (PR) por iniciativa de uma empresa que fabrica aparelhos específicos para o exercício físico de pessoas idosas. O secretário de Esportes considerou o projeto interessante $\mathrm{e}$ implementou a primeira academia em uma praça às margens de importante via de acesso à cidade. Após receber críticas elogiosas do ex-

presidente da república Fernando Henrique

Cardoso, quando de sua

visita àquela cidade, $a$

prefeitura resolveu

ampliar o número de instalações, concluindo 22 unidades.
A partir do final da década de 1990, a Organização Mundial de Saúde (OMS) institui a implementação do conceito de "envelhecimento ativo" como relevante no Sistema Único de Saúde (SUS), significando incluir, no atendimento à pessoa idosa, além dos cuidados com a saúde, ações públicas que promovam "modos de viver mais saudáveis e seguros em todas as etapas da vida", visando ao alcance de um envelhecimento mais saudável e com maior qualidade de vida. Esta proposta teve como finalidade a mudança de abordagem em relação ao envelhecimento, afastando-o da associação com o patológico, apesar de ainda associá-lo a um momento de "progressivas limitações": "[...] o maior desafio na atenção a pessoa idosa é conseguir contribuir para que, apesar das progressivas limitações que possam ocorrer, elas possam redescobrir possibilidades de viver sua própria vida com a máxima qualidade possível" (Brasil, 2006, p.9, grifo nosso).

Tivemos, como universo empírico, os discursos dos profissionais e dos responsáveis pela implementação das políticas públicas de saúde da pessoa idosa, bem como as significações desses discursos por parte dos(as) idosos(as) em um município de médio porte no Estado de Santa Catarina. Foram realizadas entrevistas no período de maio a julho de 2008, junto a 14 idosos(as), sendo dez mulheres e quatro homens com idade entre sessenta e oitenta anos, todos(as) aposentados ou pensionistas, residentes em moradia própria e com escolaridade básica concluída (três entrevistadas haviam frequentado o primeiro ano do ensino médio).

Dentre os responsáveis pela implementação e coordenação de ações de educação e promoção da saúde para a Terceira Idade no município, foram entrevistados sete profissionais: Secretário de Saúde, Coordenadora do Programa de Saúde da Família, Coordenadora da Vigilância Epidemiológica, Diretora da Terceira Idade da Secretaria de Bem-Estar Social, Secretário da Fundação Municipal de Esportes, Presidente de uma Associação para a Terceira Idade, Assistente Social e Coordenadora da Associação. Não entrevistamos a Secretária de Educação, cuja agenda, pelo que nos foi informado, estava lotada em função de tratar-se de "ano eleitoral".

A população idosa foi contatada nas "Academias da Terceira Idade", localizadas nas praças públicas da cidade, e em encontros semanais promovidos pela Associação da Terceira Idade. O local e as entrevistas ocorreram em dias e horários por eles(as) determinados. Os(as) responsáveis pelas ações e implementações das políticas municipais de educação e promoção de saúde foram contatados(as) por telefone, agendando-se a entrevista de acordo com a disponibilidade de datas dos(as) entrevistados(as) e o cronograma para a realização da coleta de dados ${ }^{9}$.

$\mathrm{Na}$ análise dos dados, buscamos entender os modos como os discursos são produzidos no âmbito político e como estes mesmos discursos, consubstanciados nas práticas, são subjetivados pelos sujeitos aos quais se dirigem. Quais efeitos de verdade têm os discursos que delineiam um ideal de comportamento saudável para as pessoas - em especial, as idosas?

No caso do envelhecimento, a "política" de prevenção tem assumido dois modelos básicos no município pesquisado, conforme aferido mediante as entrevistas: a) acompanhamento e cuidados prestados a idosos(as) portadores de Doenças Crônicas Não-transmissíveis (DCNT), mais especificamente diabéticos e hipertensos, nos "hiperdia" ${ }^{10}$; e b) busca de mudanças de comportamento através das Academias da Terceira Idade ${ }^{11}$.

Essas "academias", montadas em praças do município, disponibilizam aparelhos de ginástica e recebem supervisão de monitores - estudantes ou professores de Educação Física - durante duas horas na parte da manhã e duas ao final da tarde. A escolha das praças para instalação das "academias atendeu ao critério básico de localização tanto do ponto de vista da visibilidade pública quanto do maior número de bairros circunvizinhos. Tal critério excluiu idosos(as) residentes em bairros mais 
periféricos, uma vez que o sistema de transporte da cidade é precário ${ }^{12} \mathrm{e}$ oferecido por uma única empresa pública.

Os discursos dos(as) gestores(as) são marcados por excessiva ênfase nas atividades físicas, tomando-se a possibilidade de oferta e de multiplicação das academias como aspecto central na política de saúde do(a) idoso(a). Tal raciocínio calcado em "oferta de serviços" coloca em tensão o próprio comportamento do(a) idoso(a), pois Ihe são atribuídas as escolhas de estilo de vida: deste modo, eles(as) próprios(as) passam a ser implicitamente considerados(as) os(as) responsáveis por possibilidades de ocorrências danosas à saúde.

Como mostra Foucault (1998), o entendimento que cada sujeito tem de si e do mundo é balizado pelas relações entre falso e verdadeiro, preconizadas na dinâmica de poder-saber. Surge daí o que pode e deve ser pensado, ou os chamados regimes de verdade.

Nos discursos oficiais, em que a condição de ser idoso é igualada a um estado de fragilidade orgânica e a correr risco de adoecer, individualiza-se o(a) idoso(a) como aquele(a) que não é capaz, que precisa ser cercado(a) de cuidados, de atenção especial. A ele(a) são oferecidas oportunidades - sobretudo de atividades físicas - e sobre ele(a) recai a responsabilidade de a elas aderir para ser saudável. Tais entendimentos sobre o(a) idoso(a) reafirmam os discursos epidemiológicos da saúde, nos quais o risco assume o lugar de predizer e de legitimar as medidas de prevenção em saúde.

A partir do século XX, o modelo de exercício de poder - designado por Foucault (1999) como biopoder - inaugura novo entendimento dos saberes biomédicos, voltado para a "governabilidade das populações". É a biopolítica, que institui mecanismos de acompanhamento e do controle de endemias, da taxa de reprodução e dos óbitos, dentre outros.

Assim, podemos dizer que a regulação do corpo coletivo e a noção de bemestar social foram possíveis a partir daí. Exercitar-se, caminhar, ir às academias são atividades supervalorizadas pela política local, efetuando um estreitamento de noções, tais como qualidade de vida e autonomia, preconizadas pelas políticas públicas. Por meio desses investimentos nos corpos dos indivíduos idosos, são ativados controles sociais que incidem sobre essa faixa etária.

Ao serem questionadas sobre o que consideram essencial em relação a sua saúde, as pessoas idosas entrevistadas (aqui identificadas por nomes fictícios) revelam saberes ativados pela tecnologia do biopoder:

"O mais importante que eu considero na minha saúde nos dias de hoje é a atividade física, a caminhada". (Ana)

“[...] é com medicamento adequado [...] procurando os meios como academia que a gente tem, da terceira idade, alongamento, dança essas coisa...". (Joana)

"Muito lazer, muita ocupação, exercícios físicos, caminhadas, enfim qualquer esporte que me leve assim a ter prazer". (Antonia)

"Fazer exercícios, ficar ativos, ter amigos, fazer passeios". (Lúcia)

Nestes exemplos, "velhice ativa" é claramente equiparada à atividade física. Outros "bons hábitos" também aparecem, sem tanta ênfase e com menos frequência: é importante alimentar-se bem, passear, socializar-se. Entretanto, é sobretudo em relação ao exercício físico do corpo, loco de controle e de

\author{
${ }^{12} \mathrm{O}$ sistema rodoviário \\ urbano é mantido por \\ uma única empresa \\ pública de transporte. \\ Possuindo grande \\ extensão territorial \\ $\left(2.651,04 \mathrm{~km}^{2}\right), \mathrm{o}$ \\ município tem um de \\ seus pontos críticos no \\ transporte, pois as linhas \\ funcionam em intervalos \\ longos - podendo \\ chegar a uma hora - para \\ atender os bairros mais \\ periféricos. Destaca-se \\ ainda que a área rural é \\ de $2.429 \mathrm{~km}^{2}$, enquanto \\ a área urbana é de \\ apenas $222,4 \mathrm{~km}^{2}$, \\ ficando um significativo \\ contingente populacional \\ com atendimento de \\ transporte extremamente \\ precário, ou mesmo sem \\ acesso a este serviço \\ público. Após as 23 horas \\ não há mais circulação de \\ ônibus na cidade.
}


investimentos na sociedade ocidental contemporânea, que se devem concentrar os esforços, sendo esse o passaporte para a saúde.

Analisando a história ocidental, Foucault identifica a existência de várias formas de subjetivação do sujeito, forjadas por meio de variadas tecnologias com o intuito de tornar o indivíduo "mensurável", "adaptável" e "produtivo". É possível equiparar tais tecnologias, principalmente, aos exercícios físicos, como evidenciado nos extratos acima. Destaca Soares (2006, p.79):

A ginástica é essa pedagogia que incide sobre o corpo individual e auxilia na regulagem do corpo social, na regulagem das populações, é tanto disciplina quanto regulamentação da vida e vai, de certo modo, em certa medida, dando visibilidade ao que poderíamos denominar corpo sadio, corpo dócil, compondo um registro de saberes sempre reelaborados e disseminados.

Na mesma direção se alinham as falas dos(as) responsáveis pelas ações públicas de saúde no município, na resposta oferecida à questão referente a serviços e a programas disponíveis no município para a promoção de saúde da pessoa idosa:

“[...] nas atividades físicas, é onde a gente tem pautado bastante, é ... o nosso enfoque, né? É, com profissionais de educação física, fisioterapia que trabalham com grupos nos diversos bairros da cidade [...]. É a questão das Academias da Terceira Idade, né, que a gente em parceria com a Fundação Municipal de Esportes é tem atuado, e nós já temos seis academias hoje funcionando, teremos 11 até o final desse mês e, até outubro, 22 instaladas. É um projeto que deu muito certo, a população reconhece isso [...] a gente ver as pessoas, né, que estão buscando, estão exigindo até, é abaixo assinado. Tenho um inclusive aqui agora com mais de mil assinaturas de um determinado bairro, pedindo pra que lá seja instalada uma academia, ou seja, a gente conseguiu unir a nossa necessidade, né, de promover e prevenir com a vontade da população. Eu acho que essa é a melhor solução quando você consegue que todo mundo trabalhe é, com esforço unificado com um mesmo objetivo". (Secretário de Saúde)

"Essencial na realidade não só a atividade física, mas esse tipo de entrelaçamento que essas pessoas têm". (Superintendente de Esportes)

“[...] pra mim, a saúde do idoso integra na alimentação, exercício físico e praticamente a auto-estima [...] com a criação dessas academias agora da Terceira Idade muita gente melhorou tanto na parte do exercício, da a.. (sic) e praticamente também a convivência com as pessoas nos bairros melhorou bastante. $\mathrm{O}$ que eu tenho escutado... conversado com eles assim pessoas que eles não sentavam mais sozinhos, não tinham mais o equilíbrio, totalmente desequilibrados...". (Diretora Associação)

Para entendermos o que está em jogo nas políticas do corpo e, neste caso, em especial, nas políticas de saúde da terceira idade, convém lembrar que o poder é sempre relacional e se exerce em práticas hegemônicas e sujeitas a transformação. Isto significa dizer que há maior eficácia das várias formas de poder "quando atuam discretamente na produção de realidades e efeitos desejados por meio de processos disciplinares e normalizadores" (Duarte, 2006, p.47).

Multiplicam-se os efeitos dessa política, evidenciando, como bem mostrou Foucault (1998), que o poder não é apenas repressivo, mas seu exercício produz múltiplos investimentos, acionando motivações, desejos e expectativas.

Os discursos das idosas equiparam saúde, prazer e exercícios físicos e, assim, validam a política adotada no município. Os(as) gestores(as) investem na "vontade dos idosos", tomando-a como reforço dos direcionamentos assumidos: "a população reconhece isso [...] a gente ver as pessoas, né, que estão buscando, estão exigindo até, é abaixo assinado [...]." Trata-se de intervenções políticas que garantem a 
visibilidade e o apoio da população. O biopoder tem, como base, os processos de normalização para que, além de disciplinar as condutas, seja possível "implantar um gerenciamento planificado da vida das populações", para que seja especialmente efetivo ali onde aparentemente ele não tem a ver, onde aquilo do que se trata é o "homem", "a vida", o "corpo", ou o "caráter humanitário". Desse modo, é possível identificar o poder que o Estado quer manter sobre a vida - elemento político por natureza - nas "intervenções políticas que visam incentivar, proteger, estimular e administrar o regime vital da população" (Duarte, 2006, p.50).

O fenômeno da biopolítica, entendido na prática cotidiana disseminada pelo poder estatal, fica evidenciado nas ditas "políticas públicas de saúde na terceira idade", cujo investimento preponderante no município se dá com a implantação das Academias da Terceira Idade. Por meio de discursos tidos como "politicamente corretos", na medida em que vêm ao encontro das diretrizes de promoção e prevenção de saúde preconizadas pela PNSPI, o disciplinamento dos corpos nas práticas de vida cotidiana da pessoa idosa fica patenteado, assim como a responsabilização dos próprios sujeitos pela prevenção e promoção da sua saúde.

\section{Cidadania e diversidade: noções que ajudam a refletir sobre a educação em saúde para os(as) idosos(as)}

Consideramos que esses discursos, ao estabelecerem certo modo de vida adequado para os(as) idosos(as), produzem sujeitos e subjetividades. O que poderíamos aprender a partir de outras vozes, que desestabilizam o que está aí colocado?

A área atualmente conhecida como Educação Popular em Saúde ${ }^{13}$ atua em uma vertente alinhada, sem dúvida, com a humanização, equidade e justiça social. Tem sido adotada e divulgada por autores como Brandão (1982), Vasconcelos (2001, 1997) Valla $(1999,1998)$ e Stotz (1998), e possui princípios metodológicos calcados nos pressupostos pedagógicos de Paulo Freire ${ }^{14}$.

Como esclarece Vasconcelos (1997, p.47):

[...] o adjetivo 'popular' presente no nome Educação Popular se refere não à característica de sua clientela, mas à perspectiva política desta concepção de educação: a construção de uma sociedade em que as classes populares deixem de ser atores subalternos e explorados para serem sujeitos ativos e importantes na definição de suas diretrizes culturais, políticas e econômicas.

A Educação Popular supera a vertente biomédica, que aborda a saúde através da doença, além de incorporar as dimensões econômica, política e sociocultural envolvidas na dinâmica saúde-doença-cuidado. Conforme enfatiza Assis (2004, p.42): "[...] a dinâmica de manter-se saudável, adoecer e se curar é atravessada pelas determinações e influências do contexto social, devendo aí se remeter como possibilidade da construção de um pensar sobre o viver, sobre os constrangimentos que impedem a qualidade de vida e as alternativas buscadas para superá-los".

É importante lembrar que a Educação Popular não entende a educação como processo de produção de sujeitos que apenas reproduzem ações tidas como saudáveis, mas sim como um processo que abre caminho para o exercício pleno da cidadania, entendida aqui não apenas como liberdade de exercício pleno de direitos e de realização de escolhas.

\author{
${ }^{13}$ Decorrente do \\ documento A Educação \\ em Saúde que a \\ sociedade brasileira \\ necessita: carta aberta à \\ sociedade brasileira, \\ resultante do Seminário \\ sobre Promoção da \\ Saúde e Educação \\ Popular e $2^{\circ}$ Fórum de \\ Saúde OPAS/OMS/UNB, \\ realizado em Brasília, em \\ 4 de agosto de 2000 . \\ ${ }^{14}$ Educador e intelectual \\ brasileiro, natural do \\ Estado de Pernambuco, \\ Paulo Freire (1921-1997) \\ é mundialmente \\ reconhecido por suas \\ ideias e métodos \\ inovadores no campo \\ educacional. Dentre sua \\ vasta produção literária \\ destacam-se obras como \\ Pedagogia do Oprimido \\ (1968), Educação: prática \\ da liberdade (1967) \\ Extensão ou \\ Comunicação(1982), \\ Pedagogia da Esperança \\ (1992) e Pedagogia da \\ Autonomia: saberes \\ necessários à prática \\ educativa (1997).
}


O diferencial proposto pela Educação Popular se traduz em uma prática que inclui não só os saberes do sujeito no processo de promoção de saúde, mas estimula, desenvolve e promove a cidadania. $\mathrm{Na}$ contramão desse entendimento sobre educação popular, a noção de educação como estrutura formal, vinculada a ações específicas, caracteriza os discursos oficiais no Município em questão. Educação e saúde são vistas de forma estanque, prevalecendo uma linha de pensamento político-administrativa dissociada de ações integradoras:

"Eu não tenho conhecimento assim, ó, especificamente da área da educação do município, né? Eu sei que a gente tem diversos trabalhos, tem grupos de idosos na Secretaria de Promoção Social, né? Mas eu, assim, não tenho um conhecimento específico de que atividades eles realizam, mas eu acho que é fundamental como a gente colocou anteriormente, né? Porque através da educação e do conhecimento é que eles vão buscar o serviço, eles vão entender o porquê que eles têm direito ou o que eles não têm direito a determinadas atividades, né?" (Secretário de Saúde)

"Bom, acho que a educação é fundamental né? Porque eu acho que pra gente, é, ter um idoso, é, com qualidade de vida lá no final, a gente, acho que já tem que pensar mais tarde se a gente tem que começar com educação em todos os níveis, seja lá no primeiro nível, né? [...] Hoje tem aquele, na verdade o CEJA, é alfabetização pra qualquer idade que a gente sabe que lá existe um específico pra pessoa idosa. Ações bem específicas realmente não tem". (Diretora da Terceira Idade)

Outras falas, bem menos frequentes, evidenciaram deslocamentos rumo a visões mais abrangentes e integradas. Assim, foi possível identificar em alguns discursos a ideia de integração e de ação educativa como possibilidades embutidas em todas as ações de vida cotidiana.

"A educação, eu acho que ela tá envolvida em todos os processos né? Não se tem transformação de nada, né? se a gente quer uma qualidade de vida a gente precisa né? estar com a educação é... acontecendo. Então, que que eu vejo assim, ó! Que todos os momentos aonde você faz uma orientação, é um trabalho educativo. Seja é lá no consultório, seja lá no domićlio, no grupo, em todos os momentos eu acho que a educação, ela está ocorrendo". (Coord. Programa de Saúde da Família)

"Acredito que a educação, independente da formação, eu acredito assim, que o papel é de todos. Desde o agente de saúde, do técnico de enfermagem, do médico, da enfermeira, eu acho que cada pessoa que tão vinculada aos programas, por exemplo, o PSF, tem que ter uma capacitação, né?, uma educação continuada, né?, pra eles poderem ter esse essa rede de atendimento, né?, porque às vezes a ... a visita domiciliar é muito importante e a pessoa que, que faz a visita é um agente de saúde, então ele é a referência do que tá acontecendo na comunidade. Então, a princípio, teria-se que trabalhar bem independente do nível de graduação, de formação, trabalhar toda essa equipe, essa rede de atendimento". (Assistente Social Associação)

A exemplo do campo da educação popular, encontramos teóricos e estudiosos dos estudos culturais, como Giroux (1999) e Silva (2002), que têm contribuído sobremaneira para o questionamento das práticas educativas. Suas reflexões no âmbito da promoção e da educação em saúde na terceira idade são fundamentais quando se trata de desconstruir binarismos presentes nos discursos de educação em saúde e indagar sobre a formação do profissional de saúde que irá trabalhar com grupos de pessoas vulneráveis e/ou fragilizadas, como é o caso da maioria dos idosos brasileiros.

Os estudos culturais, ao abordarem a diversidade existente dentro de cada cultura, analisam não só as relações de poder e de dominação constituídas entre nações, etnias, gêneros e orientações sexuais, mas sobretudo como tais relações assimétricas produzem movimentos de exclusão, resistência, hibridização cultural e identidades múltiplas. 
A evidência do caráter constituinte dos discursos, conforme postulado por Foucault, é incorporada aos estudos culturais, ajudando a questionar noções que essencializam o sujeito, imobilizando-o em categorias predefinidas e fixas. Fundamentando ações educativas múltiplas, os estudos culturais vêm servindo de ponto de partida para ações comprometidas com a democracia e a cidadania.

Conforme esclarece Giroux (1999), a educação construída sobre um alicerce de oposições binárias de certo/errado, adequado/inadequado, além de ter legitimado, ao longo dos séculos, relações de opressão, de dominação e de exclusão social, também estabeleceu uma hierarquia entre os povos: o europeu colonizador e os outros, os colonizados. Nessa representação colonialista, o outro é sempre classificado no polo negativo da relação, sendo assim marginalizado. Superar essa dicotomia de pensamento instituída permite admitir a diversidade, a diferença, a multiplicidade e a complexidade.

A metáfora do colonialismo é útil para questionar a herança de pensamento por meio de oposições binárias, que dá lugar à classificação do sujeito como bom ou ruim, capaz ou incapaz, culto ou inculto.

As ações de educação em saúde na terceira idade, ainda são restritas e calcadas em juízos dicotômicos, como aqueles que enquadram idosos(as) como capazes/incapazes, lúcidos(as)/ demenciados(as) ou ágeis/lentos. Tal modo de pensar e de significar o envelhecimento impede uma ação real que integre a diversidade e as múltiplas potencialidades das pessoas idosas. Além do que, contribui para a subjetivação das pessoas idosas, estruturada na incapacidade e na fragilidade, conforme observado nos discursos:

"[...] porque o idoso normalmente é aquele que precisa de mais coisa, mais remédio, né? , mais atendimento e coisa assim". (João)

"[...] a pessoa idosa, ela tem muita dificuldade, né?". (Joana)

“[...] as pessoas estão muito desorientadas. Elas vão ao banco, elas têm dificuldade na naquelas máquinas, elas têm ... Enfim, eu acho que elas tão precisando um pouco mais de atendimento específico assim pro que, naquilo que elas precisam". (Antonia)

Ver através de outras lentes, de filósofos e pensadores que questionam pressupostos do fenômeno educativo e práticas prevalentes, ajuda a repensar a promoção e a educação em saúde na terceira idade rumo a outras formas de direcionar e de gerar ações que estimulem o pleno exercício da cidadania. Em outras palavras, a vertente crítica-reflexiva da educação permite-nos efetuar deslocamentos importantes em relação aos discursos e práticas instituídos.

\section{Considerações finais}

A saúde da pessoa idosa vem se transformando nas últimas três décadas em importante evento político. A ênfase dada aos discursos que associam promoção de saúde do(a) idoso(a) a comportamentos de autodisciplina e de atividade física não problematizam devidamente a questão. Entre outros aspectos, é ignorado que o envelhecimento não constitui um processo linear e determinista e tem de ser analisado a partir de uma realidade complexa e contextualizada.

As noções de saúde/doença, resistência, força, agilidade, prazer, sofrimento e dor estão impressas no corpo. É a partir do corpo, também, que a sociedade imprime o seu controle sobre os sujeitos, conforme alerta Foucault (1998). Assim, o binômio corpo-saúde constitui, na atualidade, objeto de grande investimento político, em especial junto à população idosa.

No interior do discurso que aponta a saúde como decorrente apenas de um "estilo de viver", como identificamos em nosso estudo, é possível detectar o silenciamento de questões sanitárias e políticoadministrativas, assim como o reflexo do empobrecimento crescente da sociedade capitalista globalizada.

As estratégias biopolíticas utilizadas pelos governos depositam a responsabilidade pelas doenças e morbidades associadas ao envelhecimento nos hábitos de vida e nas escolhas pessoais. Contribuem para certos entendimentos da população sobre "condições de vida saudável", que excluem uma multiplicidade de fatores que constituem as possibilidades do exercício pleno da vida humana, quando 
passam a vincular saúde a atividade física e a práticas corporais que se destinam a romper com o sedentarismo, excluindo completamente do processo as graves mazelas sociais.

Conforme Castiel e Alvarez-Dardet (2007), os países cuja distribuição de renda se caracteriza por forte desigualdade, como é o caso do Brasil, apresentam graves "patologias sociais" que produzem corpos frágeis, enfermos e vulneráveis. Adotar especificamente a prática de exercícios físicos como principal estratégia para a promoção de um envelhecimento saudável, é buscar instituir um paradigma por demais reducionista e de exacerbada responsabilização pessoal para a questão da saúde da população idosa brasileira.

É importante esclarecer que reconhecemos a importância das ações que se destinam a estimular a prática de atividade física pela população idosa; entretanto, entendemos que devem vir junto a múltiplas outras dimensões essenciais para a vida plena e saudável - aspectos culturais, condições básicas de vida que dizem respeito à moradia, trabalho, lazer e acesso aos serviços de saúde. Assim, preocupamo-nos com a excessiva ênfase na ginástica como promotora de saúde, o que denuncia a perda da perspectiva da totalidade e da complexidade do ser humano e de todas as outras dimensões de saúde e de educação que deveriam estar sendo contempladas.

O que visamos evidenciar neste artigo, sobretudo, foi o caráter disciplinador dos discursos de "orientações para uma vida saudável" da pessoa idosa, que patologizam este momento de vida, individualizam a responsabilidade pela saúde e subjetivam os(as) idosos(as) para certas maneiras de ser que os(as) enquadram em uma perspectiva reducionista de vida. Tais discursos que buscam apenas legitimar o que seria entendido como vida saudável ou sedentarismo, ou normal e anormal para a saúde, assujeitam-nos (Foucault, 1987).

\section{Colaboradores}

Wânia Ribeiro Fernandes foi responsável pela coleta e análise dos dados e redação do artigo; Vera Helena Ferraz de Siqueira foi responsável pela revisão da análise dos dados e redação do manuscrito.

\section{Referências}

ASSIS, M. Promoção da saúde e envelhecimento: avaliação de uma experiência no ambulatório do Núcleo de Atenção ao Idoso da UnATI/UERJ. 2004. Tese (Doutorado) Escola Nacional de Saúde Pública Sérgio Arouca, Escola Nacional de Saúde Pública, Fundação Oswaldo Cruz, Rio de Janeiro. 2004.

BAHIA, I. A janela demográfica, crescimento econômico e as políticas de saúde e proteção social. Cad. Saude Publica, v.13, n.4, p.1112-3, 2008.

BEAUVOIR, S. A velhice. Rio de Janeiro: Nova Fronteira, 1990.

BRANDÃO, C.R. Lutar com a palavra: escritos sobre o trabalho do educador. Rio de Janeiro: Graal, 1982.

BRASIL. Secretaria de Atenção à Saúde. Política Nacional de Saúde da Pessoa Idosa. Departamento de Atenção Básica - Brasília: Ministério da Saúde, 2006.

As cartas da Promoção da Saúde. Brasília: Ministério da Saúde. 2002a. Disponível em: <http://www.saude.gov.br/bvs/conf_tratados.html>. Acesso em: 14 fev. 2004. 
BRASIL. Ministério da Saúde. Vamos promover nossa saúde? Brasília. 2002b. Ministério da Saúde. Política Nacional de Saúde do Idoso. 1999. . Ministério da Saúde. Sistema Nacional de Saúde. In: CONFERÊNCIA NACIONAL DE SAÚDE, 5., 1975, Brasília. Anais... Brasília, 1975. p.399. 1973. Ministério da Saúde. Política Nacional de Saúde. Brasília: Ministério da Saúde,

BUSS, P.M. Uma introdução ao conceito de promoção da saúde. In: CZRESNIA, D. (Org.) Promoção da saúde: conceitos reflexões, tendência. Rio de Janeiro: Fiocruz, 2003. p.15-38.

Promoção e educação em saúde no âmbito da Escola de Governo em Saúde da Escola Nacional de Saúde Pública. Cad. Saude Publica, v.15, n.2, p.177-85, 1999.

CAMARANO, A.A. Os novos idosos brasileiros: muito além dos 60 . Rio de Janeiro: IPEA, 2004.

CANDEIAS, N.M. Conceitos de educação e de promoção em saúde: mudanças individuais e mudanças organizacionais. Rev. Saude Publica, v.31, n.2, p.209-13, 1997.

CASTIEL, L.D.; ALVAREZ-DARDET, C. A saúde persecutória: os limites da responsabilidade. Rio de Janeiro: Fiocruz, 2007.

DOWNIE, R.S.; TANNAHILL, C.; TANNAHILL, A. Health promotion: models and values. Oxford: OUP, 1996.

DUARTE, A. Biopolítica e resistência: o legado de Michel Foucault. In: RAGO, M.; VEIGA-NETO, A. (Org.). Figuras de Foucault. Belo Horizonte: Autêntica, 2006. p.75-85.

FERNANDES, W.R. Educação em saúde da pessoa idosa: discursos oficiais e subjetivações no Município de Lages, SC. 2010. Tese (Doutorado) - Núcleo de Tecnologia Educacional para a Saúde, Universidade Federal do Rio de Janeiro, Rio de Janeiro. 2010

FOUCAULT, M. A arqueologia do saber. 6.ed. Rio de Janeiro: Forense Universitária, 2002.

Em defesa da sociedade. São Paulo: Martins Fontes, 1999.

Microfísica do poder. Rio de Janeiro: Graal, 1998.

Vigiar e punir. Petrópolis: Vozes, 1987.

GIROUX, H.A. Cruzando as fronteiras do discurso educacional: novas políticas em educação. Porto Alegre: Artes Médicas, 1999.

KALACHE, A. O mundo envelhece: é imperativo criar um pacto de solidariedade social. Cad. Saude Publica, v.13, n.4, p.1107-11, 2008.

MACEDO, C.G. Notas para uma história recente da saúde pública na América Latina. Brasília: OPAS - Representação no Brasil, 1977.

MONTEIRO, C.A.; BENÍCIO, M.H.D.; FREITAS, I.C.M. Melhorias em indicadores de saúde associados à pobreza no Brasil dos anos 90: descrição, causas e impacto sobre as desigualdades regionais. São Paulo: NUPENS/USP, 1997.

ORGANIZAÇÃO DAS NAÇÕES UNIDAS. Plano de ação internacional contra o envelhecimento. Trad. Arlene Santos. Brasília: Secretaria Especial dos Direitos Humanos, 2002. (Série Institucional em Direitos Humanos, v.1).

PAZ, S.F. Espelho, espelho meu... imagens que povoam o imaginário social da velhice e do idoso. Rio de Janeiro: CBCISS, 1997.

SILVA, T.T. Documentos de identidade: uma introdução às teorias do currículo. Belo Horizonte: Autêntica, 2002. 
SINGER, P.; CAMPOS, O.; OLIVEIRA, E.M. Prevenir e curar: o controle social através dos serviços de saúde. Rio de Janeiro: Forense Universitária, 1978.

SOARES, C.L. Pedagogias do corpo: higiene, ginásticas, esporte. In: RAGO, M.; VEIGA-NETO, A. (Org.). Figuras de Foucault. Belo Horizonte: Autêntica, 2006. p.75-85.

STOTZ, E.N.; VALLA, V.V. Desenvolvimento de habilidades pessoais. In: BUSS, P.M. (Coord.). Promoção da saúde e a saúde pública: contribuição para o debate entre as Escolas de Saúde Pública da América Latina. Rio de Janeiro: Fiocruz, 1998.

VALLA, V.V. Sobre a participação popular: uma questão de perspectiva. Cad. Saude Publica, v.14, supl.2, p.7-18, 1998.

Educação Popular, saúde comunitária e apoio social numa conjuntura de globalização. Cad. Saude Publica, v.15, supl.2, p.7-14, 1999.

VASCONCELOS, E.M. Redefinindo as práticas de saúde a partir da Educação Popular nos serviços de saúde. In: (Org.). A saúde nas palavras e nos gestos: reflexões da Rede de Educação Popular e Saúde. São Paulo: Hucitec, 2001. p.11-20.

Educação Popular nos serviços de saúde. 3.ed. São Paulo: Hucitec, 1997.

VEIGA-NETO, A. Foucault \& a educação. 2.ed. Belo Horizonte: Autêntica, 2005.

VERAS, R. Envelhecimento populacional contemporâneo: demandas, desafios e inovações. Rev. Saude Publica, v.43, n.3, p.548-54, 2009.

FERNANDES, W.R.; SIQUEIRA, V.H.F. Educación en salud del anciano en discursos y prácticas: actividad física como sinónimo de salud. Interface - Comunic., Saude, Educ., v.14, n.33, p.371-85, abr./jun. 2010.

En este artículo presentamos una discusión sobre la educación y la promoción en salud del anciano con base en estudio empírico de cuño cualitativo que tuvo por objeto analizar los modos en que los discursos se producen en el ámbito político y como son subjetivados. Obtuvimos los datos a partir de entrevistas semi-estructuradas realizadas con ancianos (as) y profesionales directamente relacionados con la implementación de las políticas públicas de salud dirigidas a la población anciana. Tras breve discusión de las directrices preconizadas por tales políticas, presentamos los resultados, los cuales ponen en evidencia que los profesionales atribuyen a la actividad física la principal estrategia para la promoción de una "vejez saludable" y que los discursos de los ancianos reproducen, en gran medida, estas construcciones. La noción foucaultiana de bi-poder y algunas nociones oriundas de los estudios culturales nos ayudaron a entender como los individuos optan por la subjetividad en relación a lo que se preconiza como modo saludable de vivir.

Palabras clave: Discursos. Educación en salud. Promoción de la salud. Ancianos. Bio-poder. 